\title{
Penentuan Waktu antar Pemesanan Optimal untuk Model Persediaan Probabilistik Multi-Item dengan All-Units Discount dan Kendala Kapasitas Gudang
}

\author{
Handi Koswara $^{* 1)}$, Dharma Lesmono ${ }^{2)}$ \\ ${ }^{1)}$ Jurusan Teknik Industri, Fakultas Teknologi Industri, Institut Teknologi Nasional, Bandung, Jalan PHH. Mustafa 23, \\ Bandung, 40124, Indonesia \\ 2) Jurusan Matematika, Fakultas Teknologi Informasi dan Sains, Universitas Katolik Parahyangan, Jalan Ciumbuleuit 94, \\ Bandung, 40141, Indonesia
}

DOI: 10.20961/performa.17.1.17504

\begin{abstract}
Abstrak
Suatu pengelolaan persediaan yang baik merupakan hal yang sangat penting bagi suatu perusahaan, terutama karena terkait dengan biaya yang melekat pada persediaan itu sendiri. Pada umumnya, dalam mengatur persediaan, perusahaan perlu menentukan jumlah pemesanan dan waktu antar pemesanan yang optimal. Terkadang, supplier memberikan diskon dan perusahaan cenderung untuk memanfaatkan diskon ini walaupun perusahan perlu mempertimbangkan kapasitas gudang yang tersedia. Di dalam paper ini akan dikembangkan model persediaan multi-item probabilistik dengan keterbatasan gudang. Dengan menggunakan kondisi-kondisi Kuhn-Tucker akan dikembangkan sebuah algoritma untuk memperoleh waktu pemesanan yang optimal. Dari contoh numerik dengan mempertimbangkan berbagai kapasitas gudang yang tersedia, diperoleh bahwa jika kapasitas gudang diperbesar maka biaya total akan berkurang. Berdasarkan parameter yang digunakan, kapasitas minimum gudang yang diperlukan agar perusahaan memanfaatkan all-units discount adalah 1,316.875 satuan volume.
\end{abstract}

Kata Kunci: persediaan, multi-item, all-units discount, keterbatasan kapasitas gudang, kondisi-kondisi Kuhn-Tucker

\section{Abstract}

A good inventory management becomes crucial for a company since it is related to some inventory costs. In managing inventory, in general we need to determine the optimal order quantity and the optimal time to order. In some cases, when supplier offers discount, a company tends to accept this offer although it needs to consider its storage capacity. In this paper, we develop a multi-item probabilistic inventory model with all-units discount and storage space restriction. We employed the Kuhn-Tucker Conditions and developed an algorithm to find the optimal order policy. From the numerical experiments, considering different values of storage capacity, we found that when the storage capacity increases then the optimal time to order and the optimal quantity increase making the total cost decreases. Based on the parameters we used in the numerical experiments, the minimum capacity of storage that the company needed to take all-units discount is 1,316.875-unit volume.

Keywords: inventory, multi-item, all-units discount, storage space restriction, the Kuhn-Tucker Conditions

\section{Pendahuluan}

Suatu pengelolaan persediaan atau inventory yang baik merupakan hal yang sangat penting bagi suatu perusahaan, terutama karena terkait dengan biaya yang melekat pada persediaan itu sendiri. Biaya-biaya tersebut (relevant costs) umumnya meliputi biaya pemesanan, biaya penyimpanan, dan biaya kekurangan (stock-out cost) (Ballou, 2004). Keseimbangan antara biaya pemesanan dan biaya penyimpanan merupakan hal penting yang perlu diperhatikan dalam pemesanan barang. Di satu sisi, pemesanan barang yang terlalu banyak akan menyebabkan biaya penyimpanan yang besar (biaya pemesanan relatif kecil), tetapi di sisi lain jika pemesanan terlalu sedikit akan menyebabkan biaya pemesanan menjadi besar (biaya penyimpanan relatif kecil), karena frekuensi pemesanan menjadi lebih besar. Biaya lain yang perlu diperhatikan adalah biaya kekurangan, yang muncul ketika permintaan lebih besar dari persediaan. Hal ini terkait dengan apa yang disebut service level, yaitu kemampuan perusahaan untuk memenuhi permintaan dari pelanggan. Secara umum, hampir tidak mungkin suatu perusahaan mencapai service level $100 \%$ terutama di dalam kondisi ketidakpastian permintaan dan keterbatasan biaya persediaan. Dalam hal ini, pengelolaan service level dalam kaitannya dengan ketidakpastian permintaan dan biaya persediaan menjadi sesuatu yang penting.

Persediaan dapat dipandang sebagai sumber daya yang menganggur yang akan dijual kepada konsumen, yang memerlukan tempat penyimpanan dengan kapasitas yang tidak tak terbatas. Jika perusahaan menganut prinsip just-in-time, maka tentunya perusahaan tidak memerlukan atau hanya memerlukan tempat penyimpanan

\footnotetext{
*Korespondensi : handi.koswara@itenas.ac.id
} 
dengan kapasitas yang tidak terlalu besar. Tetapi dalam banyak kasus, perusahaan tetaplah memerlukan tempat penyimpanan barang dengan kapasitas tertentu. Dengan memperhatikan kapasitas penyimpanan barang yang dimiliki, perusahaan perlu melakukan pemesanan dengan jumlah yang optimal agar dapat meminimumkan biaya persediaan dalam periode waktu tertentu.

Dalam banyak kasus, seringkali pihak pemasok (supplier) memberikan diskon untuk pemesanan barang yang melebihi suatu kuantitas tertentu. Kesempatan ini dapat dimanfaatkan oleh perusahaan untuk membeli barang dengan jumlah yang lebih banyak tetapi tetap perlu memperhatikan sejumlah faktor, diantaranya adalah kapasitas gudang yang dimiliki. Jika kapasitas gudang terbatas, maka perusahaan tersebut tidak dapat memanfaatkan diskon yang ditawarkan oleh supplier secara optimal. Oleh karena itu, diperlukan suatu pengaturan dalam menentukan jumlah pemesanan yang memperhatikan kapasitas gudang yang tersedia.

Pada penelitian-penelitian sebelumnya, Tamjidzad dan Mirmohammadi (2015) telah mengembangkan model $(\mathrm{r}, \mathrm{Q})$ single item pada suatu sistem persediaan stokastik dengan all-units discount dan kendala sumber daya. Giri dan Roy (2013) mengembangkan model persediaan dengan quantity discount dan jumlah pengiriman yang berbeda-beda. Sarkar dkk. (2013) mengembangkan suatu model persediaan dengan tingkat pemenuhan permintaan tertentu, kebijakan kredit dan tawaran diskon. Mousavi dkk. (2014) menggunakan algoritma particle swarm optimization untuk masalah pengendalian persediaan multi-item dengan mempertimbangkan inflasi dan diskon. Papachristos dan Skouri (2003) mengembangkan suatu model persediaan untuk barang-barang yang memiliki waktu kadaluarsa dengan mempertimbangkan diskon, harga dan backorder yang bergantung pada waktu. Taleizadeh dan Pentico (2014) mengembangkan suatu model economic order quantity (EOQ) dengan backorder parsial dan all-units discount. Sementara itu, Cárdenas-Barrón dkk. (2015) mengembangkan suatu pendekatan untuk menyelesaikan masalah persediaan multi-item dengan multi-periode dengan pemilihan pemasok.

Pada penelitian sebelumnya, Lesmono dan Limansyah (2017) telah mengembangkan suatu algoritma untuk menentukan jumlah pemesanan pada model persediaan multi-item dengan all-units discount. Sementara itu, Ghosh dkk. (2015) mengembangkan suatu model persediaan multi-item untuk barang-barang dengan masa kadaluarsa dengan permintaan bergantung pada persediaan dan keterbatasan kapasitas gudang. Di dalam praktik, perusahaan tidak hanya menjual satu jenis barang dan kapasitas gudang yang dimiliki adalah terbatas. Sementara itu di sisi lain, pihak pemasok seperti telah disebutkan di atas sering menawarkan diskon dalam bentuk all-units discount untuk pemesanan barang di atas jumlah tertentu. Dengan memperhatikan faktor dari pihak perusahaan dan pihak supplier, maka pada penelitian ini, akan dikembangkan suatu model persediaan multi-item dengan all-units discount dan keterbatasan kapasitas gudang. Selanjutnya, dikembangkan pula suatu algoritma penentuan kuantitas pemesanan yang optimal dengan memperhatikan kapasitas gudang.

\section{Model}

Pada penelitian sebelumnya (Lesmono dan Limansyah, 2017), telah dikembangkan suatu model persediaan probabilitik multi-item dengan all-units discount. Pada penelitian ini, dikembangkan suatu model persediaan dengan all-units discount dengan adanya keterbatasan kapasitas gudang. Ada beberapa asumsi yang digunakan pada penelitian ini, yaitu :

1. Permintaan barang selama lead time mengikuti distribusi Gamma.

2. Lead time diketahui dan besarnya konstan.

3. Penanganan kekurangan persediaan dilakukan dengan backorder.

4. Jumlah pemesanan akan tetap untuk setiap periode pemesanan.

Notasi yang digunakan pada penelitian ini adalah sebagai berikut :

$\begin{array}{cll}D_{i} & : \text { Banyaknya permintaan barang ke }-i \text { setiap tahun } \\ P_{i} & : \text { Harga barang ke }-i \\ h_{i} & : \text { Rasio biaya penyimpanan barang ke }-i \\ R_{i} & : \text { Titik pemesanan kembali (Reorder point) } \\ S & : \text { Biaya untuk satu kali pemesanan } \\ \pi_{i} & : \text { Biaya backorder barang ke }-i \\ T A C & : \text { Total biaya } \\ T & : \text { Waktu antar pemesanan } \\ W & : \text { Total kapasitas gudang } \\ w_{i} & : \text { Volume barang ke }-i\end{array}$


$n \quad:$ Jumlah barang

$\alpha_{i} \quad: \quad$ Shape paramater distribusi gamma barang ke $-i$

$\beta_{i} \quad: \quad$ Rate paramater distribusi gamma barang ke $-i$

Lesmono dan Limansyah (2017) telah mengembangkan model persediaan probabilistik dengan all-units discount. Biaya total dalam model ini adalah

$$
T A C(T)=\frac{S}{T}+\sum_{i=1}^{n}\left\{P_{i} D_{i}+P_{i} h_{i}\left(\frac{T D_{i}}{2}+R_{i}-E\left(X_{i}\right)\right)\right\}+\sum_{i=1}^{n} \frac{\pi_{i}}{T} \int_{R_{i}}^{\infty}\left(x_{i}-R_{i}\right) f\left(x_{i}\right) d x_{i}
$$

Pada model di atas, suku pertama menyatakan biaya pemesanan, suku kedua menyatakan biaya pembelian dan biaya penyimpanan, sedangkan suku ketiga menyatakan biaya backorder. Variabel $X_{i}$ menyatakan peubah acak dari permintaan barang ke $-i$ selama lead time dimana $x_{i}$ berdistribusi gamma dengan parameter $\alpha_{i}$ dan $\beta_{i}$. $E\left(X_{i}\right)$ menyatakan ekspektasi permintaan barang ke $-i$ selama lead time. Jika terdapat kendala kapasitas gudang, maka kendalanya adalah

$$
\sum_{i=1}^{n} w_{i} Q_{i} \leq W
$$

Karena modelnya merupakan periodic review, maka kendala pada persamaan (2) dapat diubah menjadi

$$
g(T)=\sum_{i=1}^{n} w_{i} D_{i} T \leq W
$$

Salah satu teknik optimasi yang dapat digunakan untuk menyelesaikan permasalahan pada (1) dengan kendala (2) adalah dengan menggunakan kondisi-kondisi Kuhn-Tucker (The Kuhn-Tucker Conditions).

The Kuhn-Tucker Conditions merupakan salah satu metode optimasi dimana terdapat kendala dengan tanda $\leq$. Misal diberikan permasalahan non-linear programming sebagai berikut (Winston, 2004):

$$
\min f\left(x_{1}, x_{2}, \ldots, x_{n}\right)
$$

terhadap

$$
\begin{gathered}
g_{1}\left(x_{1}, x_{2}, \ldots, x_{n}\right) \leq b_{1} \\
g_{2}\left(x_{1}, x_{2}, \ldots, x_{n}\right) \leq b_{2} \\
\vdots \\
g_{m}\left(x_{1}, x_{2}, \ldots, x_{n}\right) \leq b_{m}
\end{gathered}
$$

Teorema 1 dapat digunakan untuk mencari solusi pada permasalahan non-linear programming pada persamaan (1) dengan kendala (3).

Teorema 1. Pada permasalahan minimasi, jika $\bar{x}=\left(\overline{x_{1}}, \overline{x_{2}}, \ldots, \overline{x_{n}}\right)$ merupakan solusi optimal dari permasalahan pada persamaan (4), maka $\bar{x}=\left(\overline{x_{1}}, \overline{x_{2}}, \ldots, \overline{x_{n}}\right)$ harus memenuhi $m$ kendala dan terdapat $\lambda_{1}, \lambda_{2}, \ldots, \lambda_{m}$ yang memenuhi (Winston, 2004)

$$
\begin{array}{rlrl}
\frac{\partial f(\bar{x})}{\partial x_{j}}+\sum_{i=1}^{m} \lambda_{m} \frac{\partial g_{i}(\bar{x})}{\partial x_{j}} & =0 & & j=1,2, \ldots, n \\
\lambda_{i}\left(b_{i}-g_{i}(\bar{x})\right) & =0 & & i=1,2, \ldots, m \\
\lambda_{i} \geq 0 & i & =1,2, \ldots, m
\end{array}
$$

Model penelitian yang digunakan adalah

$$
\min T A C(T)
$$

dengan kendala

$$
\begin{gathered}
g(T) \leq W \\
T \geq 0
\end{gathered}
$$

dimana $T A C(T)$ merupakan fungsi dari total biaya yang dinyatakan pada persamaan (1). Fungsi $g(T)$ merupakan kendala dari kapasitas gudang yang dinyatakan pada persamaan (3).

Dengan kondisi-kondisi Kuhn-Tucker, dapat ditentukan solusi yang optimal dari permasalahan ini. Perhatikan bahwa

dan

$$
\frac{d T A C}{d T}=\sum_{i=1}^{n}\left(\frac{P_{i} h_{i} D_{i}}{2}-\frac{\pi_{i}}{T^{2}} \int_{R_{i}}^{\infty}\left(x_{i}-R_{i}\right) f\left(x_{i}\right) d x_{i}\right)-\frac{S}{T^{2}}
$$




$$
\frac{d g}{d T}=\sum_{i=1}^{n} w_{i} D_{i}
$$

Berdasarkan Teorema 1, diperoleh dua persamaan sebagai berikut:

$$
\begin{gathered}
\sum_{i=1}^{n}\left(\frac{P_{i} h_{i} D_{i}}{2}-\frac{\pi_{i}}{T^{2}} \int_{R_{i}}^{\infty}\left(x_{i}-R_{i}\right) f\left(x_{i}\right) d x_{i}\right)-\frac{S}{T^{2}}+\lambda \sum_{i=1}^{n} w_{i} D_{i}=0 \\
\lambda\left(\sum_{i=1}^{n} w_{i} D_{i} T-W\right)=0
\end{gathered}
$$

Perhatikan persamaan (8), jika $\lambda=0$ maka $g(T)-W<0$ atau $g(T)-W>0$. Agar persamaaan ini memenuhi pertidaksamaan (3) maka haruslah $g(T)-W<0$. Ini berarti bahwa kapasitas gudang akan cukup untuk menampung pesanan. Jika $\lambda>0$ maka $g(T)-W=0$. Hal ini berarti bahwa jumlah pemesanan dibatasi oleh kapasitas gudang.

Untuk $\lambda>0$, persamaan (8) dapat diubah menjadi

$$
\begin{aligned}
\sum_{i=1}^{n} w_{i} D_{i} T & =W \\
T & =\frac{W}{\sum_{i=1}^{n} w_{i} D_{i}}
\end{aligned}
$$

Perhatikan pada persamaan (7), variabel $\lambda$ dapat ditulis secara eksplisit sebagai berikut :

$$
\lambda=\frac{\frac{1}{T^{2}}\left(S+\sum_{i=1}^{n} \pi_{i} \int_{R_{i}}^{\infty}\left(x-R_{i}\right) f\left(x_{i}\right) d x_{i}\right)-\sum_{i=1}^{n} \frac{P_{i} h_{i} D_{i}}{2}}{\sum_{i=1}^{n} w_{i} D_{i}}
$$

Karena $\lambda>0$ dan $\sum_{i=1}^{n} w_{i} D_{i}>0$ maka

$$
\frac{1}{T^{2}}\left(S+\sum_{i=1}^{n} \pi_{i} \int_{R_{i}}^{\infty}\left(x-R_{i}\right) f\left(x_{i}\right) d x_{i}\right)-\sum_{i=1}^{n} \frac{P_{i} h_{i} D_{i}}{2}>0
$$

Pertidaksamaan (12) ekuivalen dengan

Karena nilai $T>0$ maka

$$
T^{2}<\frac{2\left(S+\sum_{i=1}^{n} \pi_{i} \int_{R_{i}}^{\infty}\left(x_{i}-R_{i}\right) f\left(x_{i}\right) d x_{i}\right)}{\sum_{i=1}^{n} P_{i} D_{i} h_{i}}
$$

$$
T<\sqrt{\frac{2\left(S+\sum_{i=1}^{n} \pi_{i} \int_{R_{i}}^{\infty}\left(x_{i}-R_{i}\right) f\left(x_{i}\right) d x_{i}\right)}{\sum_{i=1}^{n} P_{i} D_{i} h_{i}}}
$$

Ruas kanan pada pertidaksamaan (14) sama dengan formula untuk mencari $T$ optimal dari joint order (Lesmono \& Limansyah, 2017), sehingga jika nilai $T$ yang diperoleh dari persamaan (10) lebih kecil dari $T_{\text {joint }}$ maka nilai $\lambda>0$ yang berarti terdapat kapasitas gudang yang terbatas. berikut :

Untuk menentukan nilai $T$ yang memberikan nilai $T A C$ minimum, telah dikembangkan suatu algoritma sebagai

1. Tentukan nilai $T$ berdasarkan persamaan (10).

2. Tentukan harga untuk semua barang $\left(P_{i}\right)$ berdasarkan nilai $T$ yang diperoleh.

3. Tentukan nilai $T_{\text {joint }}$.

4. Jika $T \geq T_{\text {joint }}$ maka tidak ada kendala kapasitas gudang dan nilai $T$ optimum adalah $T_{\text {joint }}$. Jika $T<T_{\text {joint }}$, maka nilai $T$ yang diperoleh dari langkah 1 merupakan solusi optimal.

\section{Hasil dan Analisis}

Pada bab ini, dibahas contoh numerik dari pencarian solusi optimum dari permasalahan persediaan multi item dengan keterbatasan kapasitas gudang. Data yang digunakan adalah sebagai berikut (Lesmono dan Limansyah, 2017), dengan menambahkan harga barang untuk pemesanan yang melebihi kuantitas tertentu, dan kapasitas gudang sebesar 500 satuan volume. 
Tabel 1. Data Produk

\begin{tabular}{|c|c|c|c|c|c|c|}
\hline & \multicolumn{2}{|c|}{ Produk 1} & \multicolumn{2}{|c|}{ Produk 2} & \multicolumn{2}{|c|}{ Produk 3} \\
\hline$\overline{D_{i}}$ & 550 & & 400 & & 800 & \\
\hline$w_{i}$ & 2 & & 2 & & 2 & \\
\hline$h_{i}$ & 0,01 & & 0,01 & & 0,0 & \\
\hline$\pi_{i}$ & 1,5 & & 2 & & 1,2 & \\
\hline$P$ & & $Q<201$ & 15 & $Q<131$ & 8 & $Q<301$ \\
\hline$P_{i}$ & 10,5, & $Q \geq 201$ & 13 & $Q \geq 131$ & 7 & $Q \geq 301$ \\
\hline$\alpha$ & 5 & & 5 & & 3 & \\
\hline$\beta$ & 2 & & 1 & & 2 & \\
\hline
\end{tabular}

Berdasarkan Lesmono dan Limansyah (2017) nilai $R_{i}$ untuk produk 1, produk 2, dan produk 3 adalah 20, 10, dan 15, sedangkan biaya pemesanan untuk joint order, $S$ adalah 9 .

Berdasarkan langkah 1 pada algoritma, nilai $T$ dapat diperoleh dengan menyelesaikan persamaan (10). Nilai $T$ yang diperoleh adalah $\frac{1}{7}$ tahun. Karena $T=\frac{1}{7}$ tahun, maka harga untuk barang $1\left(P_{1}\right)$ adalah 12 , harga untuk barang $2\left(P_{2}\right)$ adalah 15, dan harga untuk barang $3\left(P_{3}\right)$ adalah 8 . Pada langkah 3 dari algoritma, nilai $T_{\text {joint }}$ dapat ditentukan. Nilai $T_{\text {joint }}$ yang diperoleh adalah 0,2903. Karena nilai $T<T_{\text {joint }}$, maka pembelian bahan baku terbatas dan $T=\frac{1}{7}$ tahun merupakan solusi optimal dengan total biaya 19.083 dan $Q_{1}=79, Q_{2}=58$, dan $Q_{3}=115$.

Dengan cara yang serupa, untuk kapasitas gudang tersedia adalah 750, 1000, dan 1250 satuan volume, waktu antar pemesanan, total biaya, dan jumlah pemesanan setiap barang dapat dilihat pada tabel 2 .

Tabel 2. Nilai $T, T A C, Q_{1}, Q_{2}, Q_{3}$ dari Kapasitas Gudang yang Berbeda-beda

\begin{tabular}{c|c|c|c|c|c}
\hline Kapasitas Gudang & $T$ optimum & $T A C$ & $Q_{1}$ & $Q_{2}$ & $Q_{3}$ \\
\hline 750 & $\frac{3}{14}$ & 19.069 & 118 & 86 & 172 \\
1000 & $\frac{2}{7}$ & 19.066 & 158 & 115 & 229 \\
1250 & $\frac{5}{14}$ & 18.266 & 197 & 143 & 286 \\
\hline
\end{tabular}

Dari tabel 2, dapat diperoleh bahwa jika semakin besar kapasitas gudang yang tersedia maka waktu antar pemesanan yang optimum akan semakin lama, kuantitas pemesanan akan semakin besar dan total biaya yang harus dikeluarkan oleh perusahaan akan semakin kecil. Hal ini terjadi karena ketika waktu antar pemesanan menjadi lebih panjang, maka perusahaan perlu memesan barang dalam jumlah yang lebih besar (kapasitas gudang masih mencukupi), sehingga dapat dengan lebih optimal memanfaatkan diskon yang diberikan oleh pihak pemasok yang akan berakibat biaya total persediaan menjadi lebih kecil.

Dari hasil ini, dapat juga ditentukan volume gudang minimum agar perusahaan tersebut dapat memanfaatkan diskon yang diberikan dari supplier. Nilai dari $T_{\text {joint }}$ dimana harga ketiga barang tersebut merupakan harga diskon adalah 0,37625 , sehingga volume gudang minimum yang diperlukan adalah

$$
\begin{aligned}
\frac{W}{\sum_{i=1}^{n} w_{i} D_{i}} & \geq 0,37625 \\
W & \geq 1.316,875 .
\end{aligned}
$$

Volume gudang minimum adalah 1.316,875 satuan volume. Jika kapasitas gudang yang tersedia adalah 1.316,875 maka waktu antar pemesanan adalah 0,37625 dan total biaya yang dikeluarkan oleh perusahaan adalah 16.638 .

\section{Simpulan dan Saran}

Pada model persediaan dimana terdapat $\mathrm{n}$ buah barang dengan all-units discount dan kendala kapasitas gudang, waktu antar pemesanan dapat ditentukan dengan suatu algoritma yang telah dipaparkan. Jika nilai $T$ yang diperoleh lebih kecil dari $T_{\text {joint }}$ maka kapasitas gudang tidak mampu untuk menyimpan barang yang dipesan dari supplier. Dari algoritma ini juga dapat ditentukan volume gudang minimum yang diperlukan. Dari contoh numerik yang digunakan diperoleh bahwa $T_{\text {optimum }}=\frac{1}{7}$ tahun dimana volume gudang yang tersedia adalah 500 satuan volume. Jika kapasitas gudang diperbesar, maka waktu antar pemesanan yang optimum akan semakin lama, kuantitas pemesanan akan semakin besar dan total biaya yang harus dikeluarkan oleh perusahaan akan semakin kecil. Volume gudang minimum yang diperlukan agar perusahaan dapat memanfaatkan diskon yang diberikan oleh supplier adalah 1.316,875 satuan volume. Untuk penelitian selanjutnya, model ini dapat dikembangkan dengan mempertimbangkan kapasitas gudang keterbatasan dana yang tersedia secara simultan. 
Pada penelitian ini diasumsikan bahwa barang tidak mengalami penurunan kualitas. Untuk barang-barang tertentu, kualitas barang akan mengalami penurunan seiring dengan berjalannya waktu. Pelibatan faktor kadaluwarsa barang ke dalam model merupakan salah satu arah untuk penelitian lebih lanjut. Dengan adanya faktor kadaluwarsa barang, maka perlu diperhatikan adanya keseimbangan antara kapasitas gudang dengan kuantitas pemesanan barang untuk memanfaatkan diskon dari supplier secara lebih optimal.

\section{Daftar Pustaka}

Ballou, R. H. (2004). Business logistics/Supply Chain Management. Pearson Prentice Hall.

Cárdenas-Barrón, L. E., González-Velarde, J. L., \& Treviño-Garza, G. (2015). A new approach to solve the multi-product multi-period inventory lot sizing with supplier selection problem. Computers \& Operations Research, 64, 225-232.

Ghosh, S. K., Sarkar, T., \& Chaudhuri, K. (2015). A multi-item inventory model for deteriorating items in limited storage space with stock-dependent demand. American Journal of Mathematical and Management Sciences, 34(2), 147-161.

Giri, B. C., \& Roy, B. (2013). A vendor-buyer integrated production-inventory model with quantity discount and unequal sized shipments. International Journal of Operational Research, 16(1), 1-13.

Lesmono, D., \& Limansyah, T. (2017, October). A multi item probabilistic inventory model. In Journal of Physics: Conference Series (Vol. 893, No. 1, p. 012024). IOP Publishing.

Mousavi, S. M., Hajipour, V., Niaki, S. T. A., \& Aalikar, N. (2014). A multi-product multi-period inventory control problem under inflation and discount: a parameter-tuned particle swarm optimization algorithm. The International Journal of Advanced Manufacturing Technology, 70(9-12), 1739-1756.

Papachristos, S., \& Skouri, K. (2003). An inventory model with deteriorating items, quantity discount, pricing and time-dependent partial backlogging. International Journal of Production Economics, 83(3), 247256.

Sarkar, B., Sana, S. S., \& Chaudhuri, K. (2013). An inventory model with finite replenishment rate, trade credit policy and price-discount offer. Journal of Industrial Engineering, 2013.

Taleizadeh, A. A., \& Pentico, D. W. (2014). An economic order quantity model with partial backordering and all-units discount. International Journal of Production Economics, 155, 172-184.

Tamjidzad, S., \& Mirmohammadi, S. H. (2015). An optimal (r, Q) policy in a stochastic inventory system with all-units quantity discount and limited sharable resource. European Journal of Operational Research, 247(1), 93-100.

Tersine, R. J. (1994). Principles of inventory and materials management. New York: Elsevier North-Holland

Winston, W. L. (2004). Operations Research Applications and Algorithms. New York: Duxbury Press. 